Voix et Images

volxetimages

\title{
Vers une maternité qui se crée : l’oeuvre de Louky Bersianik
}

\section{Karen Gould}

Volume 17, numéro 1 (49), automne 1991

Louky Bersianik

URI : https://id.erudit.org/iderudit/200941ar

DOI : https://doi.org/10.7202/200941ar

Aller au sommaire du numéro

\section{Éditeur(s)}

Université du Québec à Montréal

\section{ISSN}

0318-9201 (imprimé)

1705-933X (numérique)

Découvrir la revue

\section{Citer cet article}

Gould, K. (1991). Vers une maternité qui se crée : l'oeuvre de Louky Bersianik. Voix et Images, 17(1), 35-47. https://doi.org/10.7202/200941ar d'utilisation que vous pouvez consulter en ligne.

https://apropos.erudit.org/fr/usagers/politique-dutilisation/ 


\title{
Vers une maternité qui se crée: l'œuvre de Louky Bersianik
}

\author{
par Karen Gould, Bowling Green State University
}

\begin{abstract}
Même si une femme a envie d'avoir des enfants, elle doit bien réfléchir aux conditions dans lesquelles elle deura les élever, parce que la maternité, actuellement, est un véritable esclavage.
\end{abstract}

\section{Simone de Beauvoir}

Dans la femme il y a toujours plus ou moins de "la mère" qui répare et alimente, et résiste à la séparation, une force qui ne se laisse pas couper, mais qui essouffle les codes.

Hélène Cixous

Lorsqu'en 1949, dans sa phrase maintenant célèbre, Simone de Beauvoir affirmait qu'on ne naît pas femme, on le devient, elle dénonf̧ait toute notion de nature féminine préétablie et proclamait en même temps l'importance de la culture dans la construction des deux sexes, et surtout dans la domination de l'un par l'autre. Ainsi pouvait-elle conclure que l'instinct maternel, auquel on se réfère souvent pour expliquer aux femmes le principe déterminant leur rôle primaire de mères de famille dans la société patriarcale, est une invention de la culture des hommes plutôt qu'un don (ou une malédiction) de la nature. S’il est vrai, cependant, que sa pensée existentialiste l'a engagée dans cette prise de position antibiologique, dont l'influence se fait sentir de plus en plus dans les courants déconstructif, postmoderne et matérialiste des féminismes contemporains, il n'en est pas moins vrai que Beauvoir n'a vu dans la fonction reproductrice des femmes qu'un handicap historique 
nuisible à leur autonomie personnelle et collective ${ }^{1}$. En fait, elle n'a pu concevoir la maternité que dans les termes les plus péjoratifs et les plus aliénants. Parmi les théories féministes récentes sur la maternité, le débat * constructionniste/essentialiste * (culture/ nature), que Beauvoir semble avoir lancé, ne cesse de s'amplifier et de se compliquer ${ }^{2}$.

Encore plus critique que Beauvoir à l'égard de toute culture qui assigne une significatión secondaire au mot * femme*, Louky Bersianik inverse le fameux postulat de sa prédécesseure, se demandant plutôt comment naitre femme (dans le sens mélioratif du mot) et ne pas le devenir (dans son sens péjoratif) ? ${ }^{3}$ Comme lauteure du Deuxième Sexe, elle écrit pour examiner le mal fait aux femmes par la philosophie, la religion et la psychologie occidentales, de même que le système d'éducation, qui ont très souvent réduit la fonction sociale des femmes à la "reproduction de l'espèce " et à la préservation du foyer paternel. Ce sont ces mêmes institutions et domaines de la connaissance, déclarent Beauvoir et Bersianik, qui ont empêché les femmes de se concevoir autrement qu'en mères de famille patriarcale. Cet effort historique pour limiter la vie des femmes à une maternité interminable s'explique facilement, selon l'Euguélionne, puisque les hommes ont tout à gagner d'un prolongement illimité du service maternel:

963. Femmes de la Terre, êtes-vous des pondeuses, des reinesabeilles, des termites, des vaches à lait dans leurs stalles?

964. Je n'ai pas d'aversion pour la maternité, dit l'Euguélionne. Bien au contraire. J'en ai beaucoup cependant pour le temps qu'elle dure.

Car les Hommes n'acceptent pas d'être sevrés. Ils exigent d'être servis, nettoyés, nourris, cajolés, approuvés, excusés, encensés, jusqu'à la fin de leur vie.

[...]

965. Les Hommes, dit l'Euguélionne, prétendent qu'ils deviendront des serviteurs s'ils laissent les femmes devenir ce

1 Beauvoir compare la femme enceinte à une plante ou un animal; captive de la nature, nous dit-elle, la mère fait peur aux enfants à cause de sa condition passive qui nuit à sa liberté. Voir son chapitre sur * La Mère * dans le Deuxième Sexe, Paris, Gallimard, 1949, vol. II.

2 A ce sujet, voir une des meilleures études récentes abordant le débat féministe sur la différence des sexes: Diana Fuss, Essentially Speaking: Feminism, Nature \& Difference, New York et Londres, Routledge, 1989.

3 Louky Bersianik, *Comment naitre femme sans le devenir *, la Nouvelle Barre du jour: Le Forum des femmes, $n^{\circ} 172,1986$, p. 59; reproduit dans la Main tranchante du symbole, Montréal, les Éditions du Remue-ménage, 1990, p. 222-232. 
qu'elles sont, c'est-à-dire, des êtres libres et non plus des Mères-servantes. ${ }^{4}$

Selon l'Euguélionne, le "problème * du deuxième sexe n'est donc pas la procréativité en elle-même, mais plutôt le fait que les hommes contrôlent et perpétuent le travail maternel à leur profit. Une fois mère-domestique; la mère ne peut être que ça.

\section{Créativité et procréation}

A travers ses explorations fictives et poétiques, aussi bien que dans ses essais théoriques, Bersianik tente à son tour de reconsidérer la maternité à partir des valeur's féministes et de redéfinir le rapport entre la nature et la culture, afin de mieux comprendre la place que pourraient occuper les femmes dans une culture qui ne les caractériserait plus selon une seule fonction biologique. Et pourtant, malgré sa critique explicite de tout essentialisme biologique qui rend la femme esclave de la procréativité, Bersianik refuse d'enterrer la mère sous l'idéologie et le système de représentation qu'elle veut déconstruire. [D]onner la vie, nous affirme-t-elle, n'est pas une valeur patriarcale. En soi, ce n'est ni bon ni mauvais, mais ça nous appartient. Comme un droit et non comme un devoir. ${ }^{5} \mathrm{Ce}$ qui, de façon fondamentale, distingue son projet de celui de Beauvoir, c'est son désir d'accorder à la maternité un pouvoir créateur substantiel, car les mères créent la vie - ce qu'il y a de plus précieux et de plus compliqué, nous rappelle-t-elle - non seulement avec leur corps (nerfs, sang, os, eaux), mais aussi avec leurs émotions et leur cerveau. Bersianik résiste donc à la dichotomie traditionnelle des deux sexes qui dicte que l'un est le sexe créateur et civilisateur ${ }^{6}$ et que l'autre sexe s'immerge toujours dans l'idée de la Nature. Voilà ce qui explique l'importance de son affirmation: [l]'utérus n'est pas une. outre, c'est un atelier de création corporelle?

Se servant d'une logique perspicace et brutalement cohérente, Bersianik apporte des précisions linguistiques sur la procréation ma-: ternelle et, ce faisant, analyse l'erreur d'un langage qui attribue à la maternité une technologie de reproduction qui a l'air machinal, voire irréfléchi, au lieu de lui reconnaître sa production ardue et cruciale:

Dire qu'on a le pouvoir de se reproduire est une expression erronée, car, s'il est vrai que l'on puisse reproduire l'espèce, on

4 Louky Bersianik, l'Euguélionne, Montréal, les Éditions de la Presse, 1976, p. 302.

5 Louky Bersianik, la Main tranchante du symbole, op. cit., p. 229.

6 Ibid., p. 264.

7 Remarque tiré de son intervention dans: « Écrire au féminin: entrevue avec Denise Boucher, Madeleine Gagnon et Louky Bersianik», Québec Studies, vol. II, printemps 1984, p. 140. 
ne peut pas reproduire les individus de cette espèce, à moins d'en faire des clones de soi-même. Pour la femme, il ne s'agit donc pas d'une reproduction d'elle-même, mais d'une production par elle d'un être unique. 8

Bersianik vise de nouveau le langage patriarcal et la pensée qui l'a informé lorsqu'elle énonce des clarifications féministes sur l'expression * mère porteuse * - expression réductrice et dangereuse, à son avis, puisqu'elle nie le véritable travail de la grossesse durant laquelle la mère, et non pas le père, fait l'enfant:

Ces précisions sur la procréation sont d'une extrême importance. Car elles mettent en évidence la duplicité du langage qui, dans un premier temps, attribue au géniteur la qualité de père (paternité) au même titre que la maternité à la femme; puis, dans un deuxième temps, qui retire à celle-ci la reconnaissance de son pouvoir de faire elle-même son propre enfant, pouvoir qu'il redistribue au géniteur seul. La maternité est réduite à l'expression "porter un enfant" alors que le rôle du géniteur est élevé au rang de puissance paternelle dont le principal dérivé se concentre dans l'expression "le nom du père», expression qui consacre socialement un pouvoir dérobé aux femmes, celui de la création. 9 .

Ainsi, l'argument à la base de ces corrections à la langue défectueuse est que le travail de la maternité - durant et après la grossesse et la naissance de l'enfant - est rarement reconnu comme de la véritable création et encore moins comme une contribution active à la culture. Mais reconnaître de nos jours le choix actif de la maternité de même que la créativité dans la procréation, c'est redéfinir la notion même d'activité et de production culturelles - transformation radicale à laquelle résistent la tradition masculine et même certaines féministes.

La réhabilitation féministe de la figure maternelle que voudrait effectuer Bersianik ne peut donc s'accomplir sans innovations linguistiques considérables, puisque l'auteure cherche également une langue dans laquelle exprimer cette nouvelle sujète maternelle qui s'affirme. Encore faut-il signaler qu'une telle réhabilitation de la mère met nécessairement en question tout un système de dualismes artificiellement établis par la pensée occidentale, dualismes qui continuent à opposer (de façon hiérarchique, bien entendu) les concepts suivants: culture/nature; activité/passivité; père/mère; intellect/corps; pensée/ émotions; production culturelle/reproduction naturelle. En cela, son projet rejoint de très près certaines réflexions critiques développées

8 Louky Bersianik, la Main tranchante du symbole, op. cit., p. 97.

$9 \quad$ Ibid., p. 98. 
par Hélène Cixoús sur la nécessité de renverser tout système de pensée binaire qui fonctionne par oppositions irréconciliables ou dialectiques, car la hiérarchie y joue toujours ${ }^{10}$.

\section{Sur les traces de nos sourcières}

Pour accomplir sa déconstruction culturelle du pouvoir dominant des pères, Bersianik situe les mères, l'utérus, ainsi que les liens affectifs et physiques engendrés par la maternité au sein même des changements qui s'avèrent cruciaux à la construction d'une culture plus équitable, plus nourrissante, plus humaine. Bien que de Beauvoir et Bersianik partent d'une même critique de la culture patriarcale traditionnelle, qui a réduit les rôles féminins à ceux de mère, de sainte et de "putain", et bien qu'elles veuillent toutes les deux faire éclater les limites imposées au sujet féminin par ces représentations mystifiantes, elles ne conçoivent pas de la mềme façon les rôles possibles d'une mère "moderne" dans les champs social et symbolique et ne partagent pas le même espoir pour son avenir.

À vrai dire, Bersianik prend le contre-pied de Beauvoir lorsqu'elle met en valeur le maternel et qu'elle entreprend de repenser la réalité des mères d'aujourd'hui et de celles du passé. Concernant les représentations maternelles, on pourrait même dire que tout circule autour des mères dans ses textes: des mères exilées, ignorées et aliénées (Exil, Omicronne, Xanthippe); des mères meurtries (Clytemnestre, la mère d'Exil); des mères qui cherchent leurs filles (Déméter, Aphélie); des filles qui ont profondément besoin de mères (Adizetu, Avertine, Margot); des déesses maternelles (la grande déesse Wondjina dont la fille est l'Euguélionne); des femmes enceintes (Astéria devenue Ortygie, les femmes enceintes photographiées par Kèro dans Au beau milieu de moi ${ }^{11}$ ), et des écrivaines qui donnent la vie aux personnages (Avertine qui fait revivre la Caryatide, l'écrivaine qui engendre les personnages du Pique-niqué).

Loin de sacrifier la mère, comme l'avait fait Beauvoir, afin de promouvoir un sujet féminin libre, actif et puissant - car la mère beauvoirienne ne peut être que l'inférieure de l'homme, une domestique passive et affaiblie -, Bersianik privilégie la maternité, le symbolisme utérin, ainsi que des générations de mères, de grand-mères et une conscience matrilinéaire occultée par l'histoire des hommes:

Cette mer:[utérine] où elles sont le rocher, où elles sont le banc de poissons, la méduse transparente, le récif de coraux rouges

10. Voir, par exemple, Hélène Cixous sur la loi des oppositions dans la philosophie et la littérature europénnes dans la Jeune Née, Paris, Únion générale d'éditions, 1975 , p. $115-120(10 / 18)$.

11. Au beau milieu de moi. Photographies de Kèro. Texte de Louky Bersianik. Montréal, Nouvelle Optique, 1983. 
et blancs, cette mer dont elles se nourrissent, où elles vivent et dérivent. Bientôt elles émergent comme la banquise, elles frôlent les parois d'un long détroit. Toutes les femmes qui ont. été fabriquées dans un utérus, dit Xanthippe lla femme de Socrate], même les femmes préhistoriques, connaissent ce lieudit du vagin. Elles ne peuvent pas l'ignorer. Leur corps sait, naît, connaît le lieudit des mains, le lieudit des seins. Leur corps connaît sur le bout des orteils et des fontanelles le lieudit $d u$ corps géographique où elles ont atterri sur cette planète. ${ }^{12}$

Tout d'abord, il y a donc la quête de la mère chez Bersianik, thématique centrale à son œuvre, dont plusieurs critiques ont déjà signalé l'importance ${ }^{13}$. Car "chercher la mère." lorsqu'on est femme et écrivaine, c'est imaginer la source de sa vie et de sa propre parole; c'est se mettre sur la trace de sa sourcière - terme féministe valorisé par Nicole Houde ${ }^{14}$, entre autres; c'est se chercher enfin. En même temps, cette quête de la mère déclenche une exploration originale des liens tout-puissants entre mères et enfants, entre grand-mères et petites-filles, entre les femmes, l'histoire et le passage des générations. Ainsi, comme je l'ai remarqué ailleurs ${ }^{15}$, l'envie de la mère dans l'œuvre de Bersianik initie une redécouverte du passé, une re-mémor-isation des générations de femmes perdues - puisque passées sous silence - et le sens d'un héritage historique ${ }^{16}$ auquel les femmes ont contribué de façon marquante. À l'encontre des romans du terroir dans lesquels le sujet maternel s'inscrit dans la discontinuité, n'ayant ni ancêtre, ni lignée [...] [d]énommée, renommée coupée de sa fille elle-même en rupture d'identité avec sa grand-mère que plus rien ne relie à sa petite-fille ${ }^{17}$, l'inscription du sujet maternel dans l'œuvre de Bersianik rétablit le sens de la continuité féminine, faisant s'écrouler les murs muets de sa prison:

12 Louky Bersianik, le Pique-nique sur l'Acropole, Mońtréal, VLB éditeur, 1979, p. $47-48$.

13 Voir, en particulier, deux excellentes études: Maroussia Hajdukowski-Ahmed, "Louky Bersianik: Feminist Dialogisms *, dans Traditionalism, Nationalism, and Feminism: Women Writers of Quebec, Paula Gilbert Lewis (directrice), Westport, Conn., Greenwood Press, 1985, p. 205-225; et Jennifer Waelti-Walters, "When Caryatids Move: Bersianik's View of Culture *, dans A Mazing Space: Writing Canadian Women Writing, Shirley Neumann et Smaro Kamboureli (directrices), Edmonton, Longspoon/NeWest Press, 1986, p. 298-306.

14 Voir Nicole Houde, la Malentendue, Montréal, les Éditions de la Pleine lune, 1983, p. 11-12.

15 Voir mon chapitre, "Louky Bersianik: Language, Myth, and the Remapping of Herstory ", dans Writing in the Feminine: Feminism and Experimental Writing in Quebec, Carbondale et Edwardsville, Ilinois, Southern Inlinois University Press, 1990, p. 150-199.

16 Ibid., p. 190.

17 Janine Boynard-Frot, Un matriarcat en procès, Montréal, les Presses de lUniversité de Montréal, 1982, p. 139. 


\begin{abstract}
ailes arrivent depuis la nuit des temps elles sombres repliées $d u$ fond des âges par couches sonores de générations la marche irrépressible par-delà la mort crée la lumière blanche qui fore le passage fond les grilles en découpe le fer avec précision 18
\end{abstract}

Le désir de retrouver la mère, de retourner aux sources, et de déterrer ses racines dans un passé matrilinéaire s'accorde bien avec l'importance que Bersianik et d'autres écrivaines de sa génération voient dans une réécriture de l'histoire à travers des lieux-dits de femmes. [J]e pars sur une trace ancienne au lieu où ma mère, écrivait Carole Massé en 1979 dans Dieu ${ }^{19}$, texte qui retrace la mise en scène masculine des femmes dans l'histoire et la mise à mort de l'idée-mère de ses mémoires de tout temps avortés ${ }^{20}$. Comme une réplique à cette critique de l'occultation historique des mères, l'archéologie maternisante dans laquelle s'engage Bersianik depuis l'Euguélionne (1976) constitue un effort littéraire pour remettre nos mères dans la production active de l'histoire et de la culture, afin d'avancer une nouvelle notion de communauté historique et de récit généalogique. Il faut cependant noter que le sujet maternel occulté par l'histoire des hommes n'est pas forcément une vraie mère. Car dans l'écriture de Bersianik le terme "mère" englobe à la fois le champ du descriptif, ceux de l'expérience et du symbolique. Nos ancêtres-mères sont réellement toutes celles qui ont engendré la vie, qui nous ont nourri/e/s, protégé/e/s, soulagé/e/s et aimé/e/s avec leur corps, leur cœur, leur esprit et leurs mots.

Comme pour souligner elle-même la portée considérable de la figure maternelle dans son œuvre, Bersianik termine le Piquenique sur l'Acropole avec la réinscription mythique de l'ancien couple mère-fille: Déméter et Perséphone. Dans sa version moderne et visiblement autobiographique, la jeune écrivaine Avertine, qui meurt d'anémie pernicieuse [e]t de fragmentation (p. 211), se rend compte qu'elle ne peut naître ni écrire sans mère. Â la fin du texte, Avertine, la fille inconsolable, paraîtra donc au pied de l'énorme statue de la Caryatide pour l'implorer de quitter le monument patriarcal de l'Acropole et d'embrasser la fille-écrivaine qui insufflera la vie dans ses veines froides et remettra du mouvement dans ses plis rigides. Mais contrairement aux versions classiques du mythe de Déméter et de Perséphone dans lesquelles la mère réussit à retrouver sa fille deux saisons de l'année (printemps et été) sur quatre, ce sont

18 Louky Bersianik, Axes et eau, Montréal, VLB editeur, 1984, p. 75.

19 Carole Massé, Dieu, Montréal, les Herbes rouges, 1979, p. 16.

20 Ibid., p. 20. 
les mots affirmatifs et l'amour nourricier de la fille-écrivaine qui feront revivre la mère patriarcale statufiée, tout comme l'auteure du Pique-nique sur l'Acropole travaille avec son corps, son cœur et son intellect à la mise au monde de ses personnages et de sa vision maternative:

La chaleur circule, le marbre se fait chair, les veines s'étirent et se gorgent de sang, prends mon sang j'en ai pour deux. Ton cœur glacé comme un balancier hésite à s'élancer je te donne mon cœur. Tes paupières cristallisées ont du mal à se déplier après tant de siècles immobiles, je te donne mes larmes. Tes oreilles desséchées s'attendrissent sous les vagues de ta coiffure, tes cheveux font leur bulbe sur ton crâne frémissant, ton nez s'invente des narines nouvelles, ta bouche veut s'ouvrir et ta langue givrée sort $d u$ froid avec des picotements de monosyllabes, prends ma salive. Tes lèvres gélives fendues par le gel te font souffrir, prends mes lèvres' et guéris-toi. Tes dents s'entrechoquent pour broyer des mots, prends mes mots dans ma bouche, prends ma langue, prends mon verbe, prends mon délire, accroche-toi à mon désir, prends mon désir de naître et NAIS, prends mon désir de vivre et VIS. ${ }^{21}$

Lorsque la Caryatide commence à bouger et se transforme enfin en «TERRIBLE VIVANTE ", elle s'approche vers "nous" tout en tenant dans ses bras Avertine, la fille épuisée qui a réussi à ranimer sa mère. Nul doute que l'envie de donner la vie ici et l'intensité avec laquelle Avertine vit son "accouchement " exceptionnel se rapprochent de l'expérience de la femme enceinte comme de celle de la femme qui écrit. C'est probablement Hélène Cixous qui explique de la façon la plus provocante comment s'entrelacent accouchement, subjectivité, écriture et transformation dans l'économie libidinale des femmes:

D'être réellement en métamorphose. Plusieurs, autre, et imprévisible. Ça ne peut pas ne pas inscrire dans le corps la possibilité, bonne, d'une altération. Il ne s'agit pas seulement de cette ressource supplémentaire du corps féminin, de ce pouvoir spécifique de la production du vivant dont sa chair est le lieu, pas seulement d'une transformation des rythmes, des échanges, $d u$ rapport à l'espace, de tout le système de perception; mais aussi de l'expérience insubstituable de ces moments de tension, de ces crises du corps, de ce travail qui se fait longtemps paisiblement pour éclater dans ce temps de surpassement qu'est l'accouchement. Où elle se vit comme plus grande ou plus forte qu'elle-même. Mais aussi de l'expérience du "lien" à l'autre,

21 Louky Bersianik, le Pique-nique sur l'Acropole, op. cit., p. 226. 
tout ce qui passe par la métaphore de la mise au monde. La femme qui fait l'épreuve du non-moi entre moi, comment n'aurait-elle pas à l'écrit un rapport spécifique? 22

\section{Mythologies modernes et maternité mâle}

L'importance de la mythologie dans l'œuvre de Bersianik est déjà bien connue. Elle a toujours accordé une place majeure dans ses textes à la subversion et à la réinterprétation de la mythologie classique et judéo-chrétienne, ainsi qu'aux archétypes et métarécits culturèls qui ont défavorisé, faussé, et effacé la vie des femmes en faveur d'une optique qui glorifiait l'homme blanc privilégié. Ses efforts pour démanteler et réécrire les mythes dominants des cultures antique et européenne font partie intégrale de son projet d'écrire contre le statut de la femme promulgué par la pensée patriarcale depuis des siècles. Mais Bersianik veut en même temps attirer notre attention sur le pouvoir qu'exercent les représentations mythiques du patriarcat dans la culture contemporaine. Et sa perspective politique est tranchante là-dessus: elle demande une réinvention des structures du langage et de l'imaginaire qui inclut les femmes et qui valorise leur expérience.

Son analyse des récits archétypaux issus de l'imaginaire masculin lui fournit aussi des modèles qui l'aident à déconstruire la "logique * patriarcale responsable de l'inéquité à la base du traitement social des mères et de la représentation symbolique de la maternité. De même, cette recherche met en marche la reconstruction des origines maternelles mémorables. Lorsque Louky Bersianik fait revivre certains personnages mythologiques et historiques, comme Xanthippe et les fameuses Caryatides dans le Pique-nique sur l'Acropole par exemple, ou comme Clytemnestre-la-mèremeurtrie et Astéria, qui se transforme en île d'Ortygie pour renaître et enfanter dans Maternative, lorsqu'elle établit des analogies importantes et intratextuelles entre Avertine et Perséphone, entre la jeune Africaine clitoridectomisée Adizetu et Iphigénie, dont la mère ne pouvait empêcher le sacrifice, l'auteure insiste sur le fait que le passé habite le présent, que la pensée patriarcale continue à faire partie de notre réalité. Car ces personnages-femmes et les récits mythiques auxquels elles sont associées mettent en évidence la puissance réelle et métaphorique des mythes misogynes qui séparent les filles de leurs mères, qui approuvent le sacrifice des filles et le matricide, et qui trouvent normal l'excision de la fille qui sera mère sans organe sexuel intact, sans plaisir. Louky Bersianik se sert de la problématique de l'excision pour souligner la façon brutale dont $[\Pi] a$ 
Femme excisée se trouve souvent réduite à l'état de vagin et de femelle reproductrice ${ }^{23}$.

Mais la pensée patriarcale ne se réserve pas exclusivement aux hommes, bien entendu, puisque des femmes ont également appris à la diffuser. Retournant aux personnages du Banquet de Platon, à la mythologie grecque et en particulier à l'exemple d'Athéna, déesse d'Athènes qui a nié ses liens matrilinéaires et son propre arbre gynile 24 , Xanthippe en tire des conclusions fâcheuses pour les femmes. En fait, sa critique de la maternité mâle constitue un des points principaux de l'argumentation féministe développée dans le Pique-nique sur l'Acropole. Car s'il y a des hommes qui tentent dans leur discours de dérober symboliquement aux femmes leur fécondité et leur puissance reproductrice - des hommes comme Socrate, par exemple - , c'est qu'ils ont bien saisi non seulement la valeur culturelle de la maternité, mais aussi le fait que les femmes-mères se valorisent à leurs propres yeux ${ }^{25}$ :

Ecoutez la voix d'Athéna à Delphes se faire l'avocate des mâles pour écraser les mères. C'èst elle la-déesse-guerrière et non pas un dieu, qui est le symbole de la civilisation grecque, berceau des civilisations misogynes, de la nôtre en ce siècle encore, ici et partout. Ces temples sur cette acropole lui sont consacrés. Cette ville qui nous entoure est sa ville. Mais elle proclame qu'elle n'a pas de mère à qui elle doive la vie puisqu'elle est sortie de la tête de Zeus comme Ėve de la côte d'Adam. La grossesse d'Adam. La maternité mâle. Le Phallus pour l'Utérus. Spoliation, spoliation. Escroquerie. Supercherie. Tel est le pouvoir patriarcal institué dans le but de dépouiller les femmes de leur pouvoir afin d'en revêtir les andres. Tel est-il ce pouvoir et tel doit-il être renversé. ${ }^{26}$

\section{L'avenir sera materniste ou ne sera pas}

Lorsqu'il affirmait en 1953 que la mère était le seul archétype féminin dans la littérature canadienne-française ${ }^{27}$, Jean Le Moyne

23 Citation tirée d'Awa Thiam qui est encadrée et mise en relief dans le Piquenique sur l'Acropole, op. cit., p. 150.

24 C'est l'expression qu'emploie Louky Bersianik pour parler des personnagesfemmes dans ses textes, à travers lesquels elle a pu, nous dit-elle, retracer un tout petit sentier de notre mémoire et contribuer ainsi à nos archives imémoriques» (la Main tranchante du symbole, op. cit., p. 269.

25 Voir Hélène Cixous, la Jeune Née, op. cit., p. 166.

26 Louky Bersianik, le Pique-nique sur l'Acropole, op. cit., p. 224.

27 Jean Le Moyne, "La femme dans la civilisation canadienne-française " (1953) dans Convergences, Montreal, HMH, 1969, p. 79. Christiane Makward mentionne également cet essai dans son survol de la production des écrivaines québecoises, qui fut un des premiers à être publié aux États-Unis. Voir Christiane Makward, "Quebec Women Writers n, Women and Literature, vol. VI, $n^{\circ} 1$, hiver 1979, p. 4. 
exagérait la place qu'on lui assignait peut-être, mais il soulignait néanmoins la visibilité de l'archétype maternel ainsi que son importance idéologique dans une littérature qui se vouait généralement, tout comme la religion et la culture dont elle était issue, au thème de la survivance dont l'arme la plus sûre était, disait-on, la revanche des berceaux. Dans les textes de Bersianik, par contre, des filles insoumises et errantes telles qu'Exil et Avertine, par exemple, ne se reconnaissent plus dans la mère mystifiée par les romans du terroir et le patriarcat:

On peut dire que l'enfant est une mémoire de ses géniteurs et qu'il existe en mémoire de ceux-ci. Ainsi, la fille aurait-elle dû exister en mémoire de la femme mais cette mémoire a tellement été faussée qu'on ne reconnaît plus la seconde dans la première. Faussée, c'est-à-dire mythifiée puis interprétée non en tant que telle mais en tant que mythe. ${ }^{28}$

Si Le Moyne discernait dans le mythe de la mère l'archétype qui fournissait l'élément de base à l'idéologie conservatrice au Québec, rien de tel en effet dans l'écriture de Bersianik où des mères et des filles rebelles refusent le passé * statufié " dont elles ont hérité et pour lequel les Caryatides du Pique-nique sur l'Acropole restent une métaphore impressionnante. Contrairement à l'archétype maternel identifié par Le Moyne, qui se lie au statu quo à tout point de vue et qui fournit les colonnes colonisées [du patriarcat], soutiens d'un système qui leur est étranger et hostile ${ }^{29}$,-les mères et filles en révolte dans l'œuvre de Bersianik s'orientent plutôt vers un avenir radicalement materniste $\mathbf{3 0}$ et libératoire. En ceci, elles ressemblent plutôt aux femmes futures de certaines utopies féministes américaines qui nient les valeurs militaristes et meurtrières à l'œuvre dans la culture patriarcale. Chez Bersianik, les femmes qui transformeront l'avenir auront pour but d'établir une culture au féminin aux valeurs écologiques, culture qui 's'opposera à l'oppression des femmes, à la violence, et à l'avidité féroce de la mentalité entrepreneuriale qui traite les individus de "cheap labor» au service des autres ${ }^{31}$.

À bien des égards, l'éthique morale que préconise Bersianik correspond de très près à celle proposée par Sara Ruddick dans Maternal

28 Louky Bersianik, «Les Agénésies du vieux monde * dans la Main tranchante du symbole, op. cit., p. 239.

29 Louky Bersianik, le Pique-nique sur l'Acropole, op. cit., p. 85.

30 Jemprunte le terme de Maureen Cloutier-LaPerrière. Inspirée par les théories féministes américaines de Sara Ruddick et d'Adrienne Rich sur les valeurs maternelles, Cloutier-LaPerrière définit une culture "materniste de la facon suivante: absence de tentatives de domination et de controle, grand respect des differences individuelles, libre expression de la sexualite et la possibilite pour la femme de vivre, de penser, d'agir et de s'exprimer sans crainte. Voir son article, "La mère, la guerre et les utopies f́eministes n, Imagine, 53, vol. XI, n 4, septembre 1990, p. 27.

31 Louky Bersianik, la Main tranchante du symbole, op. cit., p. 265. 
Thinking: Toward a Politics of Peace ${ }^{32}$. Comme Ruddick, Bersianik développe une perspective féministe qui valorise le travail maternel dont un élément crucial est la conscience de la souffrance des autres ${ }^{33}$. Les femmes, dans le Pique-nique sur l'Acropole, qui prennent soin d'Adizetu comme si elle était leur fille et qui respectent leurs différences et se consolent de leur peine respective sont exemplaires de cette attitude. Ruddick et Bersianik basent toutes les deux leur éthique materniste sur des principes de non-violence, de préservation de la vie, et d'un amour maternel qui alimente les pensées ou le corps de l'autre sans se les approprier. Il faudrait également ne plus censurer la maternité active dans la production de la culture, et ne plus exiger de la fille le passage réglementaire de la mère au père ${ }^{34}$. Une vraie culture au féminin, précise Bersianik, serait une culture où les femmes, tout en créant l'utopie du futur, s'appartiendraient totalement, non seulement physiquement, mais symboliquement. 35

Après avoir vivement critiqué la brutalité des cultures viriles et la boursouflure de la pensée phallocrate, dans l'Euguélionne et le Pique-nique sur l'Acropole, c'est précisément une culture naissante aux valeurs maternelles et à l'image utopique que l'écrivaine propose dans Maternative et Axes et eau. Et le mythe de la jeune Astéria qui, poursuivie sans répit par Zeus, se transforme en île d'Ortygie pour se bercer dans la mer-mère avant de renaître et enfanter, devient la métaphore principale de ce projet. La belle histoire d'Ortygie, remarque Bersianik, c'est le commencement d'une histoire destinée à humaniser l'humanité, c'est donc le début d'une civilisation de l'avenir, l'émergence de ce que j'appelle LA GYNILIE. ${ }^{36}$ L'insistance sur le verbe naitre, dans Maternative, met en relief sa double tentative de renouvellement personnel et de reconstruction culturelle:

Enceinte liquide ajournée prête au toucher environnemental

Aux environs de la mère où vire mental le tournis de la fille

Ni encore mère ni encore fille

Mais la mer

Diurne mais la mer inchangée ce non-lieu

pour un temps à gravir vite passé

Gravite le désir de naître ${ }^{37}$

32 Sara Ruddick, Maternal Thinking: Toward a Politics of Peace, New York, Ballantine Books, 1989.

33 Ibid., p. 231.

34 Concept cher Nancy Chodorow et qui forme la base de sa critique de la psychanalyse freudienne dans son étude The Reproduction of Mothering: Psychoanalysis and the Sociology of Gender, Berkeley, University of California Press, 1978.

35 Louky Bersianik, la Main tranchante du symbole, op. cit., p. 265.

36 Ibid., p. 262.

37 Louky Bersianik, Maternative, Montréal, VLB éditeur, 1980, p. 133. 
Ainsi faut-il conclure que le domaine de la mère s'est considérablement élargi chez Bersianik. Et puisque son but, entre autres, est de redéfinir les paramètres de l'activité maternelle et de redéfinir la créativité des mères - aussi bien que des femmes en général -, l'auteure continue à développer une optique féministe qui valorise le travail maternel, qui préconise une pensée materniste et qui ne rélègue plus à l'anecdotique la vie et les contributions de nos mères et de nos ancêtres-mères. Bien que Bersianik adopte parfois un ton utopique, voire mystique dans son écriture lorsqu'elle explore le terrain autrefois tabou du corps maternel, sa réinscription du sujet maternel s'opère dans le domaine du social. Il faudrait peut-être alors concevoir à nouveau le poids de notre mémoire mythologique dans le champ culturel si l'on veut apprécier l'énergie terrible d'une re-mémorisation maternelle qui vise à transformer les mythes et le monde:

Mère totale environnementale de la verte Avertine. Ça ne vous étonne pas que j'aie rencontré Déméter? Et pourtant c'est la verte vérité. Quand les déesses vermeilles sortent de la légende pour marcher dans la. rue, c'est, qu'elles vont entrer dans l'histoire. ${ }^{38}$ 